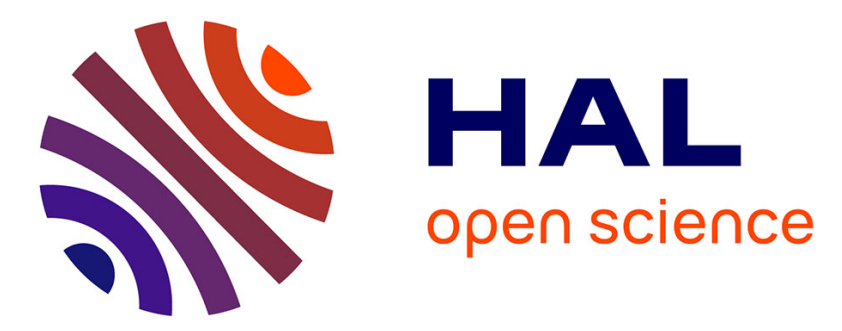

\title{
Interrupted heating DTA for liquidus temperature determination of $\mathrm{Ag}-\mathrm{Cd}-\mathrm{In}$ alloys
}

Kasi Gajavalli, Georges Mikaelian, Marc Barrachin, Alexandre Decreton, Evelyne Fischer, Jacques Rogez, Pierre Benigni

\section{To cite this version:}

Kasi Gajavalli, Georges Mikaelian, Marc Barrachin, Alexandre Decreton, Evelyne Fischer, et al.. Interrupted heating DTA for liquidus temperature determination of $\mathrm{Ag}-\mathrm{Cd}-\mathrm{In}$ alloys. Journal of Thermal Analysis and Calorimetry, 2019, 135 (4), pp.2209-2219. 10.1007/s10973-018-7442-1 . hal02557908

\section{HAL Id: hal-02557908 \\ https://hal.science/hal-02557908}

Submitted on 29 Apr 2020

HAL is a multi-disciplinary open access archive for the deposit and dissemination of scientific research documents, whether they are published or not. The documents may come from teaching and research institutions in France or abroad, or from public or private research centers.
L'archive ouverte pluridisciplinaire HAL, est destinée au dépôt et à la diffusion de documents scientifiques de niveau recherche, publiés ou non, émanant des établissements d'enseignement et de recherche français ou étrangers, des laboratoires publics ou privés. 


\title{
Interrupted Heating DTA for Liquidus Temperature Determination of Ag-Cd-In Alloys
}

Kasi Gajavallia, Georges Mikaelian ${ }^{\mathrm{b}}$, Marc Barrachin ${ }^{\mathrm{a}}$, Alexandre Decreton ${ }^{\mathrm{a}}$, Evelyne Fischer ${ }^{\mathrm{c}}$, Jacques Rogez ${ }^{\mathrm{b}}$, Pierre Benigni ${ }^{\text {b }}$

${ }^{a}$ Institut de Radioprotection et de Sûreté Nucléaire PSN-RES, SAG, LETR, Saint Paul lez Durance cedex 13115, France

b IM2NP Aix Marseille Univ, Univ Toulon, CNRS, Faculté des Sciences de St Jérôme, Service 251, avenue Normandie-Niémen, 13397 Marseille, France

${ }^{c}$ Université Grenoble Alpes, CMTC, SIMAP, 38000 Grenoble, France

\begin{abstract}
An Ag-Cd-In alloy is used as the control rod material in most Pressurized Water Reactors (PWR). Despite this important application, the phase diagram of the Ag-Cd-In ternary system remains largely unknown especially the phase equilibria involving the liquid phase in the $\mathrm{Cd}$ and $\mathrm{In}$ rich regions. In this work, the 60 at.\% In isopleth section is investigated by Differential Thermal Analysis (DTA). The results of the classical protocol at constant heating and cooling rates are compared with those obtained using an Interrupted Heating (IHDTA) method. It is shown that this last protocol allows to strongly reduce the uncertainty on the liquidus temperature determination.
\end{abstract}

\section{Keywords}

Differential Thermal Analysis, Ag-Cd-In alloys 


\section{Introduction}

Most Pressurized Water Reactors (PWR) control rods are composed of the Ag-Cd-In neutron absorber alloy with composition 80 wt.\% Ag, 15 wt.\% In, 5 wt.\% Cd, (SIC) cladded by an AISI 304 or 316 stainless steel tube, itself inserted in a Zircaloy-4 guide tube. In severe accident conditions, Petti et al. [1] showed that the SIC control rods structures fail at $1427^{\circ} \mathrm{C}$ due to eutectic interaction between stainless steel and Zircaloy of the guide tube. The low melting point of the Ag-Cd-In alloy, the high volatility of $\mathrm{Cd}$ and the large quantities of this material in the core could potentially induce early fuel rod degradation by interaction of molten SIC with fuel rod cladding. The absorber elements also interact with fission products, affecting significantly their speciation and transport in the primary circuit as well as their behavior in containment. The quantification of the gases released and the nature of the species transported, which both depend on these interactions, are important for assessing the radiological consequence of the severe accidents.

In this framework, information on the phase equilibria involving the liquid phase of the Ag-Cd-In ternary system, especially in the $\mathrm{Cd}$ and In rich regions, is of high interest and the method of thermal analysis for this particular system is reviewed and benchmarked.

\section{Bibliography}

A brief literature review of the ternary system can be found in the recent experimental study of the Ag-Cd-In liquid mixing enthalpy [2] where a tentative isothermal section at $450^{\circ} \mathrm{C}$ is proposed. The equilibria involving the liquid phase have not been extensively studied in this system and the available results are further analyzed below.

In the silver corner of the ternary triangle, the liquid (L) is expected to be in equilibrium with the $(\alpha)$ fcc solid solution based on silver. If the stability domain of this solid solution has been established by Snyder et al. [3] at room temperatures and at $315^{\circ} \mathrm{C}$, the information on its liquidus surface is restricted to the SIC composition on which several studies have focused. The melting range of the SIC alloy is roughly estimated to be $800-850^{\circ} \mathrm{C}$ [4], but more accurate experimental values can be found from other studies. Using an induction furnace which can go up to $1627^{\circ} \mathrm{C}$, Bowsher et al. [5] heated control rod alloy in an open alumina crucible under argon. They determined the "melting point", probably referring to the liquidus temperature, of the alloy to be $827 \pm 10^{\circ} \mathrm{C}$.

Horrocks [6] determined the melting range of the SIC alloy to be $725-830^{\circ} \mathrm{C}$ by DSC using open crucible under argon. The liquidus temperature measured on cooling was higher than the end of melting detected during the former heating run. This effect was the result of Cd vaporization according to the author. The experiment was repeated with a new sample and the liquidus value obtained by averaging the results of both experiments was reported to be $825.5^{\circ} \mathrm{C}$. The melting range of the SIC alloy was very recently determined by Steinbrück and Stegmaier [7] on heating at $15^{\circ} \mathrm{C} \mathrm{min}^{-1}$. The SIC sample was enclosed in a gas tight steel capsule to avoid $\mathrm{Cd}$ vaporization. The solidus temperature, identified as the onset of the DSC peak, and liquidus temperature, identified as the peak maximum, were reported at 743 and $831^{\circ} \mathrm{C}$ respectively.

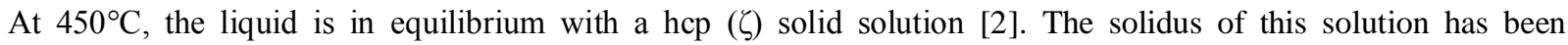
determined by EDS analysis on samples equilibrated in the $(\zeta+\mathrm{L})$ domain at $450^{\circ} \mathrm{C}$ before quenching in water. Three points on the liquidus curve at $450^{\circ} \mathrm{C}$ were also indirectly derived from the evolution of the partial mixing enthalpy of $\mathrm{Ag}$ vs. silver mole fraction $\mathrm{x}_{\mathrm{Ag}}$ [2]. In addition, two indium rich isopleth sections corresponding to the mole fraction conditions $\mathrm{x}_{\mathrm{In}}=0.6$ and $\mathrm{x}_{\mathrm{In}} / \mathrm{x}_{\mathrm{Cd}}=3$ have been investigated respectively by Robinson and Jones using the Smith Thermal Analysis technique. The results of these unpublished studies are reported in the Horrocks doctoral thesis [6]. However, Horrocks has cast some doubts on the procedure adopted to determine the liquidus temperature in Robinson's work because, for the binary $\mathrm{Ag}_{40} \mathrm{In}_{60}$ (at.\%) alloy, Robinson reports a liquidus of $479^{\circ} \mathrm{C}$ whereas Horrocks's own measurement with the same instrument is $455.9^{\circ} \mathrm{C}$. Moreover, for the same binary composition, the liquidus temperatures measured by DSC on heating by Moser et al. [8] and Bahari et al. [9] [10] are 455 ${ }^{\circ} \mathrm{C}$ and $446.5^{\circ} \mathrm{C}$ respectively, confirming that the liquidus temperature determined by Robinson is likely to be overestimated. 
In the experimental setup used by Robinson and Jones, the sample thermocouple sheathing can be used as a stirring rod to enhance nucleation of solid phases on cooling from the liquid [6]. So it can be concluded that the samples were not hermetically sealed and that Cd loss was possible during the experiments. With a coupled TG-DTA instrument, Ball et al. [11] established Cd losses for a SIC composition to occur between 550 and $820^{\circ} \mathrm{C}$ under an inert atmosphere. The Cd contents of the ternary alloys studied by Jones were in the range 23-25 at.\%. Robinson investigated ternary compositions containing 3 up to 12 at.\% Cd. According to Horrocks [6], the highest thermal arrests detected by Robinson and Jones were respectively $448^{\circ} \mathrm{C}$ and $244^{\circ} \mathrm{C}$. A significant Cd loss is not expected at these temperatures. However, the protocol is not described in details and the maximum temperatures effectively reached during the Smith thermal analyses are not mentioned. It remains difficult to estimate if Cd was lost during their experiments.

This literature review shows that, apart from the control rod alloy composition, the equilibria involving the liquid phase in the Ag-Cd-In ternary system are not firmly established. The derivation of liquidus points from isothermal calorimetric experiments in our previous study [2] remains indirect and not very accurate. The Smith thermal analysis data need to be reconfirmed due to uncertainty in the protocol and discrepancy with other literature results on a binary composition.

Hence, it was decided to reinvestigate the 60 at.\% In isopleth section of the ternary diagram already studied by Robinson [6] in the same range of Cd content. Three compositions containing 0,5 and 12 at.\% $\mathrm{Cd}$, and respectively denoted $\mathrm{Ag}_{40} \mathrm{In}_{60}, \mathrm{Ag}_{35} \mathrm{Cd}_{05} \operatorname{In}_{60}$ and $\mathrm{Ag}_{28} \mathrm{Cd}_{12} \mathrm{In}_{60}$, are examined in the present new thermal analysis study of the system. Emphasis is put on the accurate determination of the liquidus temperature of the alloys. The results obtained using a classical DTA protocol, at various heating and cooling rates, are compared with an Interrupted Heating DTA (IHDTA) method and existing literature data points.

\section{Materials and methods}

The purities of the elements used are listed in Table 1. Silver, cadmium and indium are first weighed in stoichiometric proportions. Cd has a high vapor pressure which reaches $1 \mathrm{~atm}$ at $1040 \mathrm{~K}$ according to [12], hence cadmium mass loss by vaporization must be avoided during sample preparation and subsequent experiments. The weighed pure constituents are transferred to a vitreous silica ampoule which is sealed under argon with an oxyacetylene torch. The ampoule is then heated in a furnace up to $1000^{\circ} \mathrm{C}$, held one hour at this temperature to ensure complete melting of $\mathrm{Ag}$ particles and their alloying with $\mathrm{Cd}$ and $\mathrm{In}$ at the liquid state before being cooled in the furnace down to room temperature.

A Setaram DSC 111 instrument which can work up to $830^{\circ} \mathrm{C}$ has been used to perform the thermal analyses. The outer diameter $(6.8 \mathrm{~mm})$ of the ampoules closely fits the inner diameter $(7 \mathrm{~mm})$ of the DSC tubes. The ampoule containing the sample is placed in the laboratory tube and an empty silica ampoule of similar weight and shape is inserted in the reference tube. The center of the ampoules are positioned in the middle of the thermopiles of $24 \mathrm{~mm}$ total length to maximize sensitivity.

Prior to the measurements, the instrument was temperature calibrated towards the melting points of pure Al, In, Sn and $\mathrm{Zn}$ using the classical DTA procedure described in the subsection below. The purities of the elements used for calibration are reported in Table 1. As the calibration results are extrapolated to zero rate, the corresponding temperature correction is also valid for the IHDTA protocol in which the holding temperatures are, by definition, measured at zero rate.

\section{Classical DTA}

The sample is first heated at $10^{\circ} \mathrm{C} \mathrm{min}^{-1}$ up to a temperature where melting is completed and then cooled to room temperature at the same rate. After this preliminary run, a good thermal contact is achieved between the sample and the ampoule. This run also helps in locating the equilibrium liquidus temperature and better define the maximum heating temperature $\left(\mathrm{T}_{\mathrm{Max}}\right)$ for the subsequent runs. In the consecutive measurement cycles, the sample is heated to $\mathrm{T}_{\text {Max }}$ then cooled to room temperature at $0.5,1,2,5$ and $10^{\circ} \mathrm{C} \mathrm{min}^{-1}$. The procedure is repeated for each sample. The characteristic temperatures are determined from the thermograms at each rate. Then, these temperatures are plotted 
versus the heating and cooling rates and extrapolated to zero rate to obtain the equilibrium values. The thermograms obtained on heating and cooling the $\mathrm{Ag}_{35} \mathrm{Cd}_{05} \operatorname{In}_{60}$ at 5 and $10^{\circ} \mathrm{C} \mathrm{min}-1$ are shown in Figure 1.

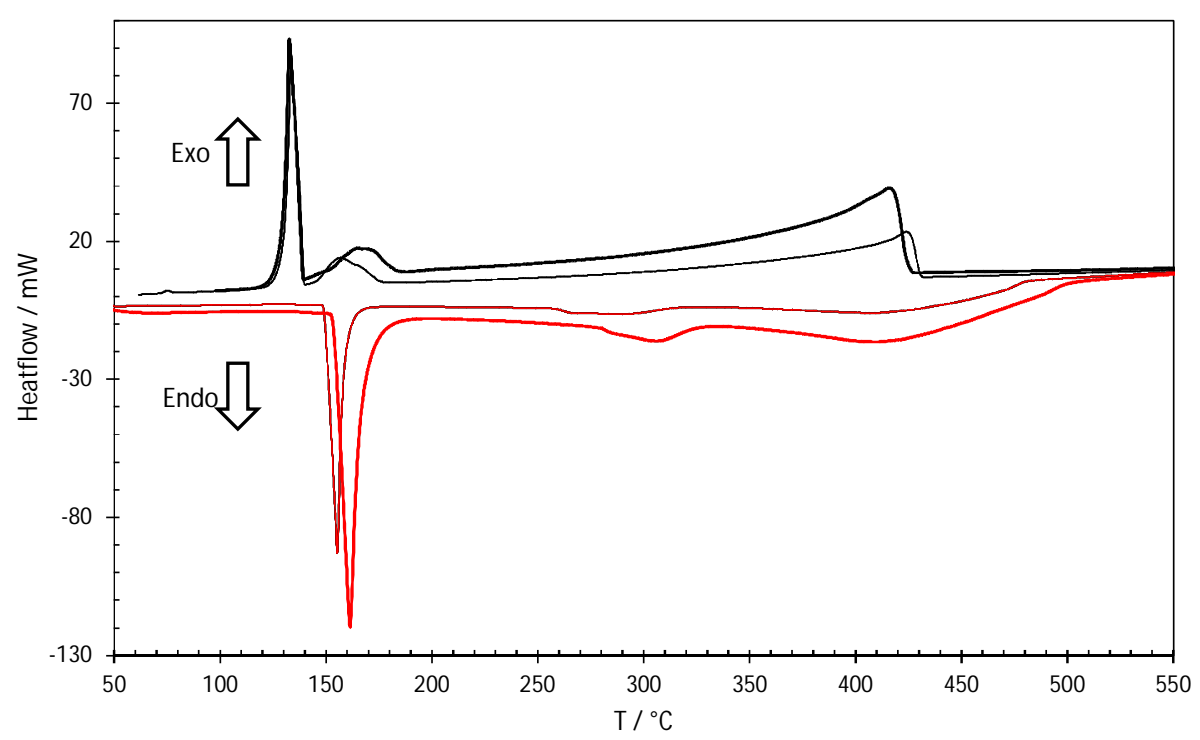

Figure 1. Heat flows obtained on heating (in red) and cooling (in black) the $\mathrm{Ag}_{35} \mathrm{Cd}_{05} \operatorname{In}_{60}$ alloy at 5 (thin line) and 10 (thick line) ${ }^{\circ} \mathrm{C} \min ^{-1}$.

Table 1. Element purities.

\begin{tabular}{lllll} 
Elements & Supplier & Commercial grade & Initial purity (mass) & Purification method \\
\hline $\mathrm{Ag}$ & Alfa Aesar & & 0.9999 & None \\
$\mathrm{Al}$ & Koch Light & & 0.99999 & None \\
$\mathrm{Cd}$ & Alfa Aesar & Puratronic & 0.999999 & None \\
$\mathrm{In}$ & Alfa Aesar & Puratronic & 0.999999 & None \\
$\mathrm{Sn}$ & Alfa Aesar & Puratronic & 0.999999 & None \\
$\mathrm{Zn}$ & Alfa Aesar & & 0.99999 & None
\end{tabular}

IHDTA

This kind of method has already been used for accurate determination of the liquidus of Sn-rich alloys in the Sn-Ag$\mathrm{Cu}$ ternary system by Moon et al. [13] and of Ni based superalloys by Wu et al. [14]. The temperature program adopted in our study is shown in Figure 2 for the $\mathrm{Ag}_{35} \mathrm{Cd}_{05} \mathrm{In}_{60}$ alloy. The sample is first heated at $10^{\circ} \mathrm{C} \min ^{-1}$ to $\mathrm{T}_{\mathrm{Max}}$ $=570^{\circ} \mathrm{C}$ at which it is fully liquid and is held isothermally at this temperature for 1 hour. The sample is then cooled at $5^{\circ} \mathrm{C} \min ^{-1}$ to $\mathrm{T}_{\mathrm{Min}}=380^{\circ} \mathrm{C}$. $\mathrm{T}_{\mathrm{Min}}$ is chosen well below the liquidus temperature to ensure that a fraction of solid is precipitated before starting a primary heating of the alloy at $5^{\circ} \mathrm{C} \mathrm{min}-1$ to the first holding temperature $\left(\mathrm{T}_{\text {Hold }}\right.$ around $420^{\circ} \mathrm{C}$ ) where it is held for 1 hour. The secondary heating is done from $\mathrm{T}_{\text {Hold }}$ to $\mathrm{T}_{\text {Max }}$ again at the same rate. This thermal cycling procedure is repeated by changing $\mathrm{T}_{\text {Hold }}$ in $3{ }^{\circ} \mathrm{C}$ increments until the estimated liquidus temperature 
upper bound (around $450^{\circ} \mathrm{C}$ ). As an example, the heat flow recorded during the third cycle is plotted vs. temperature in Figure 3.

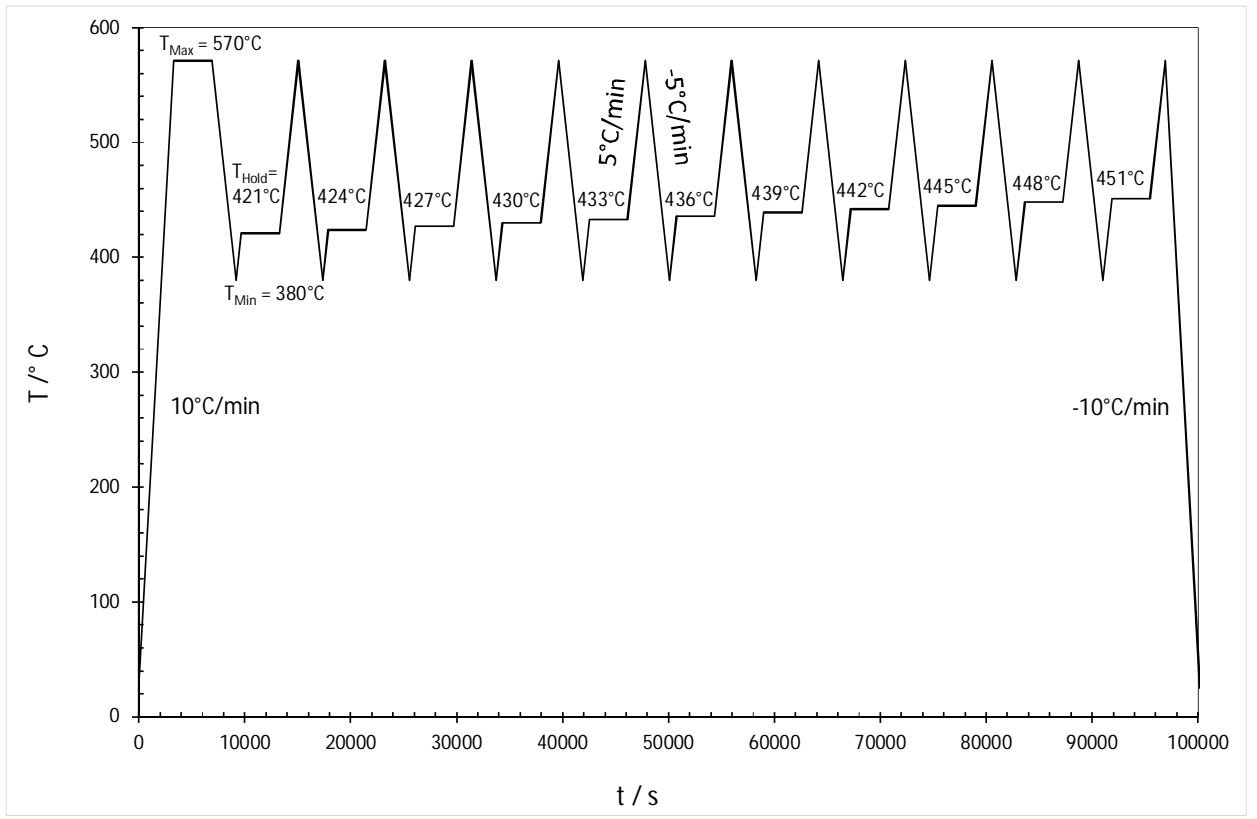

Figure 2. The IHDTA temperature vs time protocol for the $\mathrm{Ag}_{35} \mathrm{Cd}_{05} \operatorname{In}_{60}$ alloy.

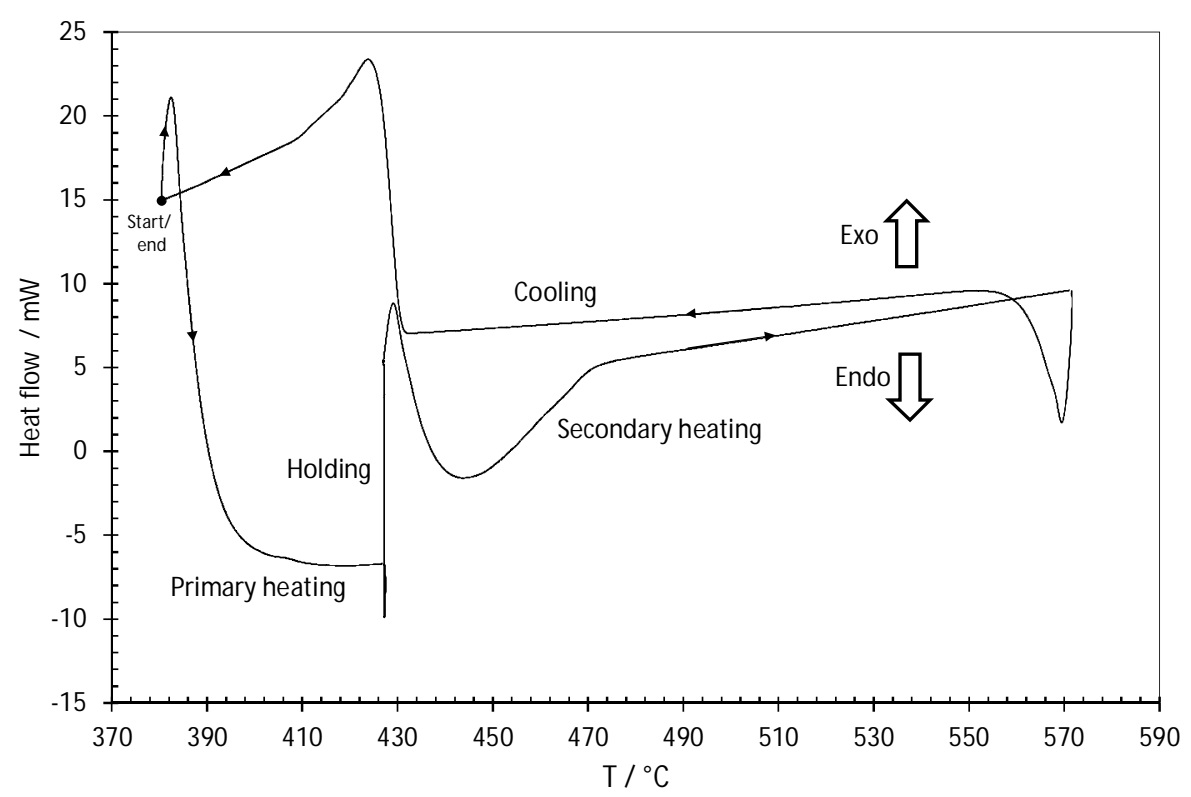

Figure 3. Heat flow recorded during the third cycle of the IHDTA protocol for the $\mathrm{Ag}_{35} \mathrm{Cd}_{05} \operatorname{In}_{60}$ alloy. Sample is heated from 380 to $427^{\circ} \mathrm{C}$, held 1 hour at this temperature, heated again from 427 to $570^{\circ} \mathrm{C}$ and then cooled back from 570 to $380^{\circ} \mathrm{C}$. The heating and cooling rates are $5^{\circ} \mathrm{C} \mathrm{min}^{-1}$. 


\section{Results}

\section{Classical DTA}

The end of the last endothermic thermal event observed on the DTA signal on heating at constant rate is considered as the liquidus temperature and usually this end coincides with the peak temperature $\left(\mathrm{T}_{\text {Peak }}\right)$ of the last endothermic peak. However, Boettinger et al. [15] showed that this might not be the case for all the alloys. They demonstrate that, for a binary alloy like $\mathrm{Bi}-10 \% \mathrm{Sb}$ exhibiting a partition coefficient $\mathrm{k}>1, \mathrm{~T}_{\text {Peak }}$ is not associated with the liquidus temperature which is rather marked by a shoulder detected on the signal at an higher temperature. On cooling at constant rate, the first exothermic rise provides a clear signature of the nucleation of the solid phase. However, the onset temperature of this rise is lower than the liquidus because of the undercooling required for nucleation. The thermograms recorded on cooling remain useful because they allow to establish a lower bound on the possible liquidus temperature.

The difficulty in determining the liquidus in Ag-Cd-In alloys is illustrated for the $\mathrm{Ag}_{35} \mathrm{Cd}_{05} \mathrm{In}_{60}$ composition. The thermograms shown in Figure 1 are zoomed in the liquidus region in Figure 4.

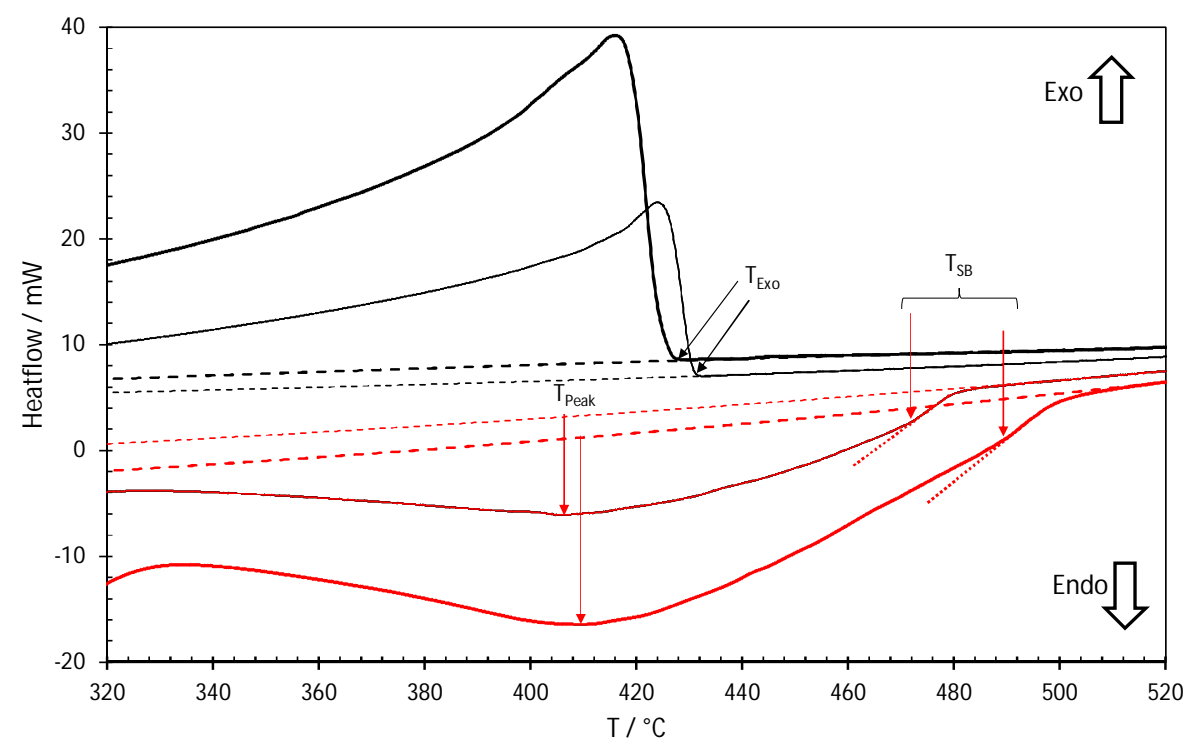

Figure 4. Heat flow recorded on heating (in red) and cooling (in black) the $\mathrm{Ag}_{35} \mathrm{Cd}_{05} \operatorname{In}_{60}$ alloy at 5 (thin line) and 10 (thick line) ${ }^{\circ} \mathrm{C} \mathrm{min}^{-1}$. Dashed lines are the interpolated baselines. Dotted lines are the extrapolated linear segments of the final return to the baseline on the heating curves. For each heating curve, the arrows mark the maximum deviation from the baseline corresponding to $\mathrm{T}_{\text {Peak }}$ and the final slope break temperature $\left(\mathrm{T}_{\mathrm{SB}}\right)$ which is the upper possible bound of the liquidus temperature. The temperature of the first exothermic rise $\left(\mathrm{T}_{\mathrm{Exo}}\right)$ on the cooling curves represents the lower bound of the liquidus temperature.

There is no sharp peak on the heating curve, and the signal is smeared over a temperature range. The peak temperatures, corresponding to the maximum deviation from the baseline, are around 408 and $412^{\circ} \mathrm{C}$ at 5 and $10^{\circ} \mathrm{C} \mathrm{m^{-1 }}$ respectively. For both heating rates, $\mathrm{T}_{\text {Peak }}$ is lower than the temperature of the exothermic rise detected on cooling $\left(\mathrm{T}_{\text {Exo }}\right.$ ) which is 432 and $427^{\circ} \mathrm{C}$ for 5 and $10^{\circ} \mathrm{C} \mathrm{min}{ }^{-1}$ respectively. Hence, it is clear that, in this case, $\mathrm{T}_{\text {Peak }}$ cannot be the liquidus temperature since it is lower than the temperature of the first exothermic rise on cooling. Moreover, reducing the heating rate down to 2,1 and $0.5^{\circ} \mathrm{C} \mathrm{min}^{-1}$ flattens the signal and renders the $\mathrm{T}_{\text {Peak }}$ determination very difficult. At these rates, the uncertainty in the interpolated baseline induces a very large uncertainty $\left(>10^{\circ} \mathrm{C}\right)$ on the $\mathrm{T}_{\text {Peak }}$ value. It is then concluded that $\mathrm{T}_{\text {Peak }}$ cannot reliably be used to derive the liquidus for our alloys. 
Hence, thermal signature of the liquidus on the heating signal should be sought between $\mathrm{T}_{\text {Peak }}$ and the temperature at which the signal join the baseline. However, in this temperature range, small fluctuations of the signal are observed but no clear thermal event is seen. The best guess for such an event is the final slope break that is indicated by an arrow in Figure 4, which marks the end of any endothermic reaction occurring in the sample. The temperatures of this slope break $\left(\mathrm{T}_{\mathrm{SB}}\right)$ are 472 and $490^{\circ} \mathrm{C}$ on heating at 5 and $10^{\circ} \mathrm{C} \mathrm{min}^{-1}$ respectively. It is worth mentioning that determination of this temperature remains to a large extent observer dependent. In the most favorable cases, it cannot be determined with an accuracy better than few degrees but in other cases, the very existence of a slope break is questionable.

The characteristic temperatures $\mathrm{T}_{\mathrm{SB}}$ and $\mathrm{T}_{\mathrm{Exo}}$ obtained from processing the DTA signals as explained above are reported in Table 2 for the three alloys under study at all heating and cooling rates and linearly extrapolated to null rate. The linear extrapolation procedure is illustrated for the $\mathrm{Ag}_{35} \mathrm{Cd}_{05} \operatorname{In}_{60}$ alloy in Figure 5.

Table 2. Characteristic temperatures $\mathrm{T}_{\mathrm{SB}}$ (on heating) and $\mathrm{T}_{\mathrm{Exo}}$ (on cooling) determined by classical DTA for the three compositions under study. Definitions of $\mathrm{T}_{\mathrm{SB}}$ and $\mathrm{T}_{\mathrm{Exo}}$ are given in the text.

\begin{tabular}{|c|c|c|c|c|c|c|}
\hline Alloy & \multicolumn{2}{|c|}{$\mathrm{Ag}_{40} \operatorname{In}_{60}{ }^{*}$} & \multicolumn{2}{|c|}{$\mathrm{Ag}_{35} \mathrm{Cd}_{05} \operatorname{In}_{60}{ }^{*}$} & \multicolumn{2}{|c|}{$\mathrm{Ag}_{28} \mathrm{Cd}_{12} \operatorname{In}_{60}{ }^{* *}$} \\
\hline Rate & Cooling & Heating & Cooling & Heating & Cooling & Heating \\
\hline$/^{\circ} \mathrm{C} \min ^{-1}$ & $/{ }^{\circ} \mathrm{C}$ & $/{ }^{\circ} \mathrm{C}$ & $1{ }^{\circ} \mathrm{C}$ & $/{ }^{\circ} \mathrm{C}$ & $/{ }^{\circ} \mathrm{C}$ & $/{ }^{\circ} \mathrm{C}$ \\
\hline 0.5 & 450 & 461 & 436 & $450^{* * * *}$ & 385 & 416 \\
\hline 1 & 449.5 & 466 & 435.5 & $456^{* * *}$ & 384 & 416 \\
\hline 2 & 449 & 468 & 435 & $461^{* * *}$ & 380 & 422 \\
\hline 5 & 446 & $464^{* * *}$ & 432.5 & 472 & 378 & 428 \\
\hline 10 & 442 & $476^{* * *}$ & 428 & 490 & - & - \\
\hline Extrapolation to 0 & $450 \pm 1$ & $463 \pm 5$ & $437 \pm 1$ & $451 \pm 5$ & $385 \pm 1.5$ & $415 \pm 2$ \\
\hline
\end{tabular}

* Samples heat treated $1 \mathrm{~h}$ at $1000^{\circ} \mathrm{C}$ before the experiments.

${ }^{* *}$ Sample melted at $700^{\circ} \mathrm{C}$ before the experiments.

**** Slope break is questionable.

- No experiment.

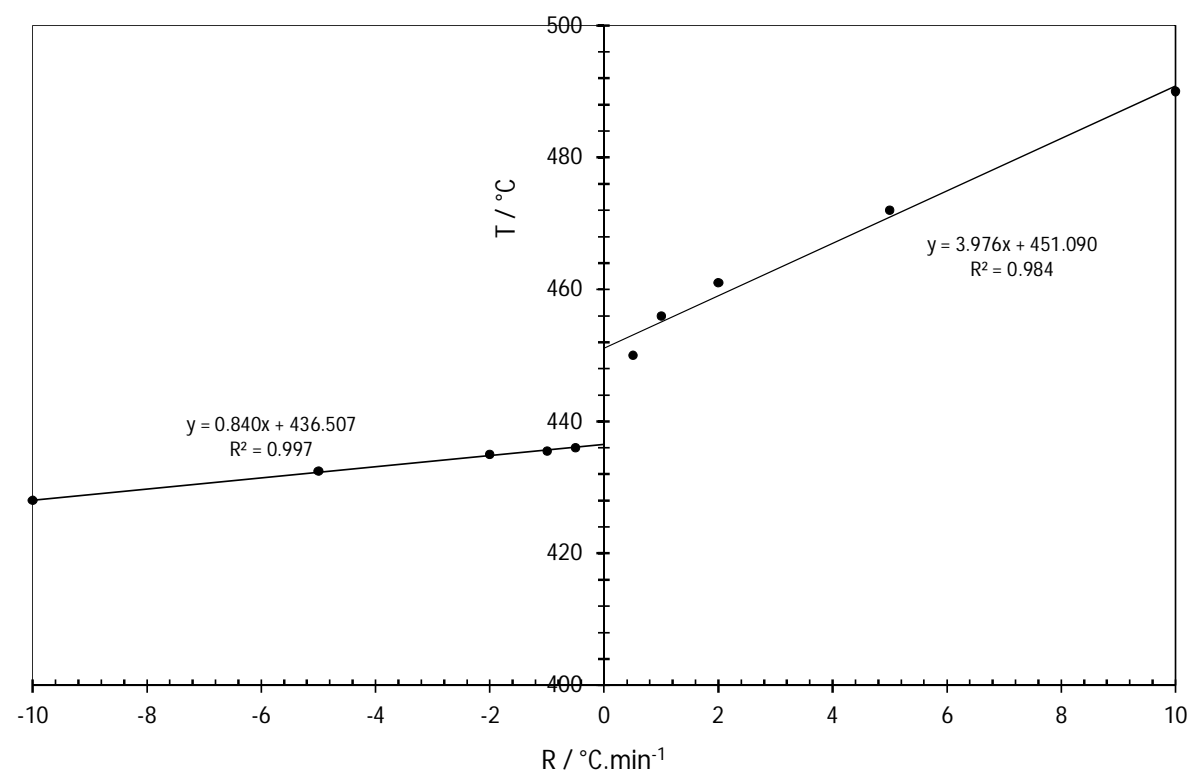


Figure 5. $\mathrm{T}_{\mathrm{SB}}$ and $\mathrm{T}_{\mathrm{Exo}}$ vs heating and cooling rates for the ternary composition $\mathrm{Ag}_{35} \mathrm{Cd}_{05} \operatorname{In}_{60}$. Zero rate values are obtained by linear extrapolation.

For the binary $\mathrm{Ag}_{40} \mathrm{In}_{60}$ composition, the liquidus is found to be in the range $450-463^{\circ} \mathrm{C}$. This estimation is consistent with the values around $455-456^{\circ} \mathrm{C}$ found by [6] and [8]. However, the value $446.6^{\circ} \mathrm{C}$ measured by [9] is likely to be underestimated since it is lower than $\mathrm{T}_{\mathrm{Exo}}=450 \pm 1^{\circ} \mathrm{C}$ detected on cooling in our experiments.

For the two ternary compositions, the temperature interval between $\mathrm{T}_{\mathrm{SB}}$ and $\mathrm{T}_{\mathrm{Exo}}$ is very large (Table 2). Taking into account the difficulties in determining $\mathrm{T}_{\mathrm{SB}}$, this value can only be considered as an upper bound of the true liquidus temperature but a reliable value could not be derived.

The possible explanation for such behavior is now further discussed.

On the basis of an unpublished tentative Calphad assessment of the Ag-Cd-In system, $\partial H / \partial T$ is calculated vs temperature for the $\mathrm{Ag}_{35} \mathrm{Cd}_{05} \mathrm{In}_{60}$ composition in Figure 6. Boettinger et al. [15] have demonstrated that such apparent heat capacity curve, when flip and broadened along the horizontal axis, gave a rough approximation of the shape of the DSC signal on melting.

As the curve in Figure 6 exhibits a sharp peak at the liquidus temperature, the DTA signal should also exhibit such feature and $\mathrm{T}_{\text {Peak }}$ should coincide with the liquidus temperature if equilibrium was maintained during the experiments, i.e. in the absence of any thermal and chemical composition gradients within the sample. It is concluded that the smoothness of the observed peaks cannot be explained by a pure thermodynamic argument.

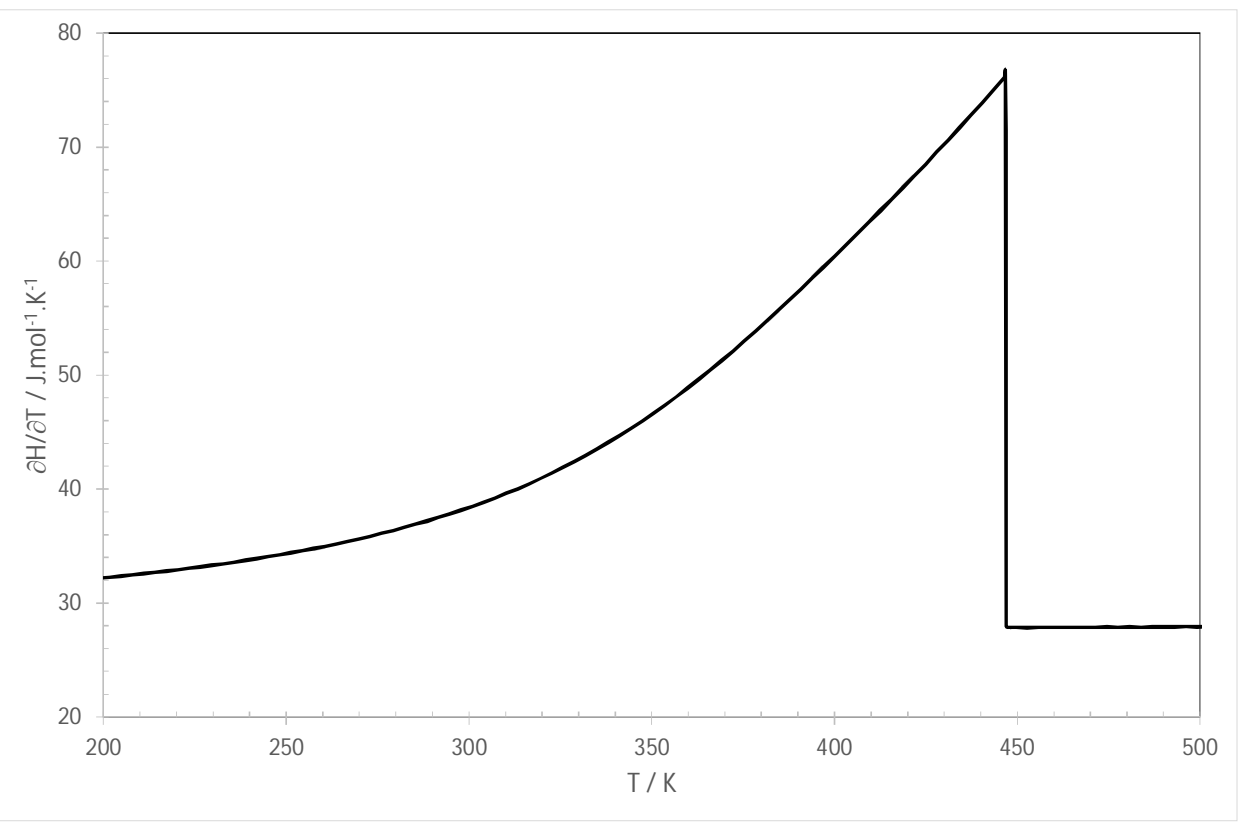

Figure 6. Calculated $\partial H / \partial T$ vs temperature for the $\mathrm{Ag}_{35} \mathrm{Cd}_{05} \operatorname{In}_{60}$ alloy at thermodynamic equilibrium on the basis of a tentative CALPHAD assessment of the ternary system.

In the composition range investigated, the first phase to form from the liquid is the hcp ( $\zeta$ ) solid solution [2]. The diffusion in this phase has not, to our best knowledge, been investigated but diffusion in substitutional solid solutions is sluggish. So, it is likely that equilibrium is not maintained under continuous heating or cooling regimes and that the initial state of the sample before heating depends on the rate which has been applied in the preceding cooling run.

\section{IHDTA}

In the IHDTA method, the sample is isothermally held for one hour at high temperature $\left(\mathrm{T}_{\mathrm{Hold}}\right)$ close to the liquidus temperature, before subsequent heating as described in the experimental section. Diffusion of the elements is thus 
enhanced by this extended period at high temperature. Moreover, as $\mathrm{T}_{\text {Hold }}$ is gradually increased, the solid fraction and the diffusion distance for homogenization in the solid also decrease [14]. So, equilibrium will be better approached by this method than by using a continuous heating rate.

The liquidus values determined by IHDTA for the three alloys are compared in Table 3 with classical DTA from this work and available literature results.

Table 3. Liquidus temperatures $\left({ }^{\circ} \mathrm{C}\right)$ determined by DTA and IHDTA methods in this work compared with available data from literature.

\begin{tabular}{|c|c|c|c|c|c|c|}
\hline \multirow[b]{3}{*}{ Method } & \multicolumn{4}{|c|}{ This work } & \multicolumn{2}{|l|}{ Literature } \\
\hline & \multicolumn{2}{|c|}{ DTA } & \multicolumn{2}{|c|}{ IHDTA $^{*}$} & \multirow[b]{2}{*}{ Smith Thermal Analysis } & \multirow[b]{2}{*}{ DTA/DSC } \\
\hline & Cooling & Heating & $\begin{array}{l}\text { Highest } \\
\mathrm{T}_{\text {Exo }} \text { on } \\
\text { cooling }\end{array}$ & Heating & & \\
\hline $\mathrm{Ag}_{40} \operatorname{In}_{60}$ & $450 \pm 1$ & $463 \pm 5$ & $444^{* *}$ & $451-454^{* *}$ & $\begin{array}{l}455.9 \text { [6] } \\
479 \text { Robinson in [6] }\end{array}$ & $\begin{array}{l}455[8] \\
446.5[9]\end{array}$ \\
\hline $\mathrm{Ag}_{35} \mathrm{Cd}_{05} \operatorname{In}_{60}$ & $437 \pm 1$ & $451 \pm 5$ & $432^{* * *}$ & $439-442^{* *}$ & - & - \\
\hline $\mathrm{Ag}_{28} \mathrm{Cd}_{12} \operatorname{In}_{60}$ & $385 \pm 1.5$ & $415 \pm 2$ & $\begin{array}{l}395^{\text {** }} \\
395^{\text {*** }}\end{array}$ & $\begin{array}{l}403-406^{* *} \\
403-404^{* * *}\end{array}$ & 423 Robinson in [6] & - \\
\hline
\end{tabular}

${ }^{*}$ All samples heat treated $1 \mathrm{~h}$ at $1000^{\circ} \mathrm{C}$ before IHDTA experiments.

${ }^{* * *}$ Heating and cooling rates $=5^{\circ} \mathrm{C} \min ^{-1}$, temperature increment $=3^{\circ} \mathrm{C}$, holding time $=1 \mathrm{~h}$.

*** Heating and cooling rates $=5^{\circ} \mathrm{C} \min ^{-1}$, temperature increment $=1{ }^{\circ} \mathrm{C}$, holding time $=3 \mathrm{~h}$.

The signal during the four stages of the IHDTA protocol namely cooling, primary heating, holding, secondary heating is further analyzed and discussed below for the $\mathrm{Ag}_{35} \mathrm{Cd}_{05} \operatorname{In}_{60}$ ternary composition for which the liquidus temperature is found to be in the range $439-442^{\circ} \mathrm{C}$.

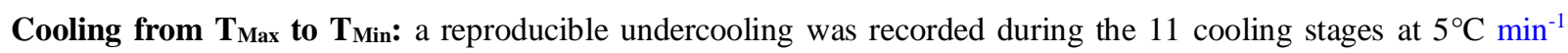
with a steep exothermic rise which occurred between 431 and $432^{\circ} \mathrm{C}$ for all the curves. This value is in excellent agreement with $\mathrm{T}_{\mathrm{Exo}}=432.5^{\circ} \mathrm{C}$ measured by classical DTA on cooling at $5^{\circ} \mathrm{C} \min ^{-1}$ (Table 2).

Primary heating from $\mathbf{T}_{\text {Min }}$ to $\mathbf{T}_{\text {Hold: }}$ this heating occurs before the holding stage on a not equilibrated sample, the signal cannot be used for the equilibrium liquidus temperature determination.

Holding: the samples are maintained 1 hour at $\mathrm{T}_{\text {Hold. }}$ The heat flow recorded during holding is plotted vs time in Figure 7. After an initial thermal transient regime, the curves tends towards constant heat flow values. However, it is observed that on increasing $\mathrm{T}_{\text {Hold }}$ from 427 to $439^{\circ} \mathrm{C}$, the duration of this transient increases accordingly. A constant value is indeed attained for all curves except possibly for the ones corresponding to $\mathrm{T}_{\mathrm{Hold}}=436$ and $439^{\circ} \mathrm{C}$. When $\mathrm{T}_{\text {Hold }}$ is further increased from 442 to $451^{\circ} \mathrm{C}$, a qualitatively different evolution of the curve shape is observed. First, the duration of the transient regime decreases and second, a slope break, indicated by an arrow, is also seen on the curves. After this break, a constant heat flow value is reached. 


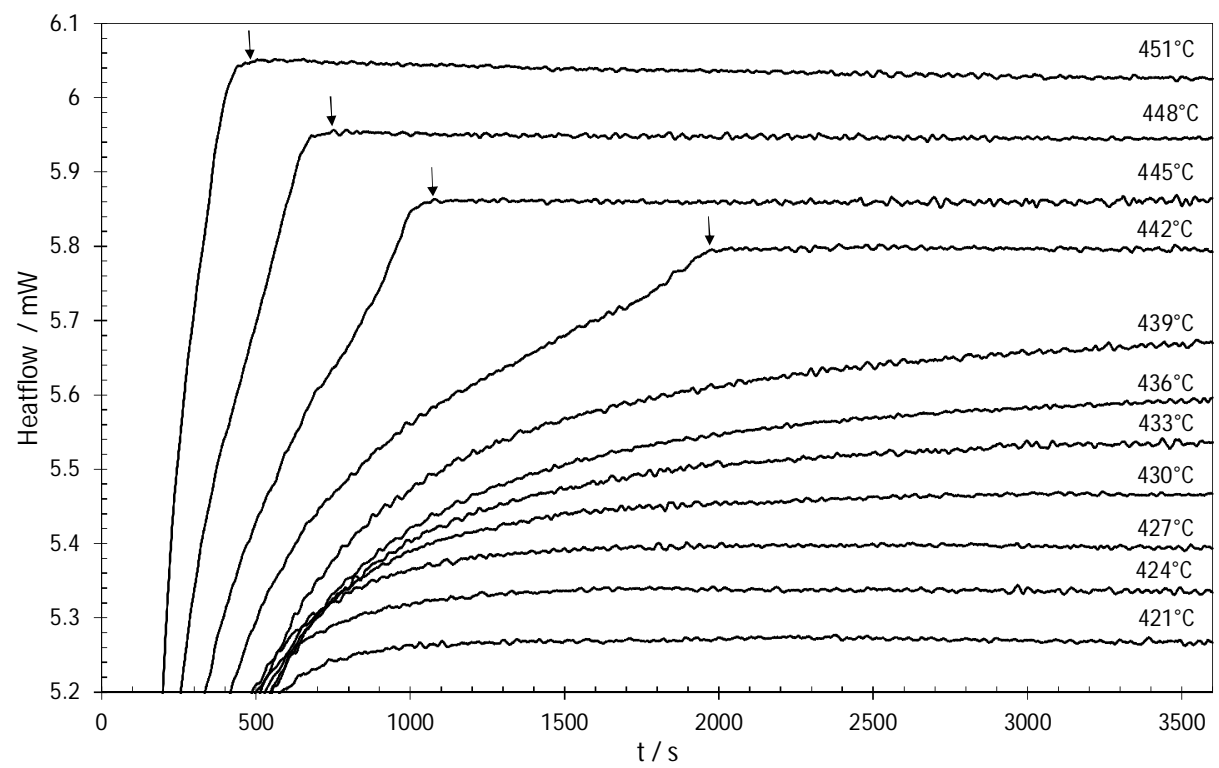

Figure 7. Holding curves for the $\mathrm{Ag}_{35} \mathrm{Cd}_{05} \mathrm{In}_{60}$ alloy. The holding time is 1 hour. Each curve is labelled with its corresponding holding temperature. For $\mathrm{T}_{\mathrm{Hold}} \geq 442^{\circ} \mathrm{C}$, the curves show a slope break marked by an arrow for each curve.

The melting behavior of the sample can be rationalized considering that the sample composition, which is heterogeneous, because of the inherited solidification microsegregation, tends to homogenize during holding, promoting its melting, and that this homogenization is diffusion controlled.

For the lowest holding temperatures, the mobility of the atoms is low and the distance on which they have to diffuse for homogenization, e.g. the half thickness of the dendritic arms, is large. As a consequence, the reaction is slow and only occurs to a very limited extent. In this case, the constant heat flow value which is attained does not mean that the samples are equilibrated. On increasing $\mathrm{T}_{\mathrm{Hold}}$ towards the liquidus temperature, and because of the combined effect of the increased mobility and of the reduced solid fraction, the homogenization/melting reaction is further enhanced.

The slope break which is seen on all the curves having a $\mathrm{T}_{\mathrm{Hold}} \geq 442^{\circ} \mathrm{C}$ is the thermal signature of the end of melting of the last superheated solid present in the sample. At these holding temperatures, concentration gradients in the solid particles are levelled off, leading to the complete melting of the sample. A fully liquid equilibrium state is attained in less than one hour. This interpretation is corroborated by the shape of the secondary heating curves as it is explained in the next paragraph.

From this analysis, it is concluded that the liquidus temperature is lower than $442^{\circ} \mathrm{C}$, where the sample is fully liquid after $2000 \mathrm{~s}$ and that the sample still contains a fraction of solid after being held one hour at $439^{\circ} \mathrm{C}$. The small positive slope of the heat flow curve vs time between 3500 and $3600 \mathrm{~s}$ at $439^{\circ} \mathrm{C}$ (Figure 7) indicates that the sample has maybe not reached equilibrium. Combining these information with the results of the classical DTA cooling runs (Table 2) brackets the liquidus temperature in the range $437-442^{\circ} \mathrm{C}$.The time necessary to reach equilibrium at 451 , 448,445 and $442^{\circ} \mathrm{C}$ is plotted vs temperature and extrapolated at $439^{\circ} \mathrm{C}$ in Figure 8 using a second degree polynomial. 


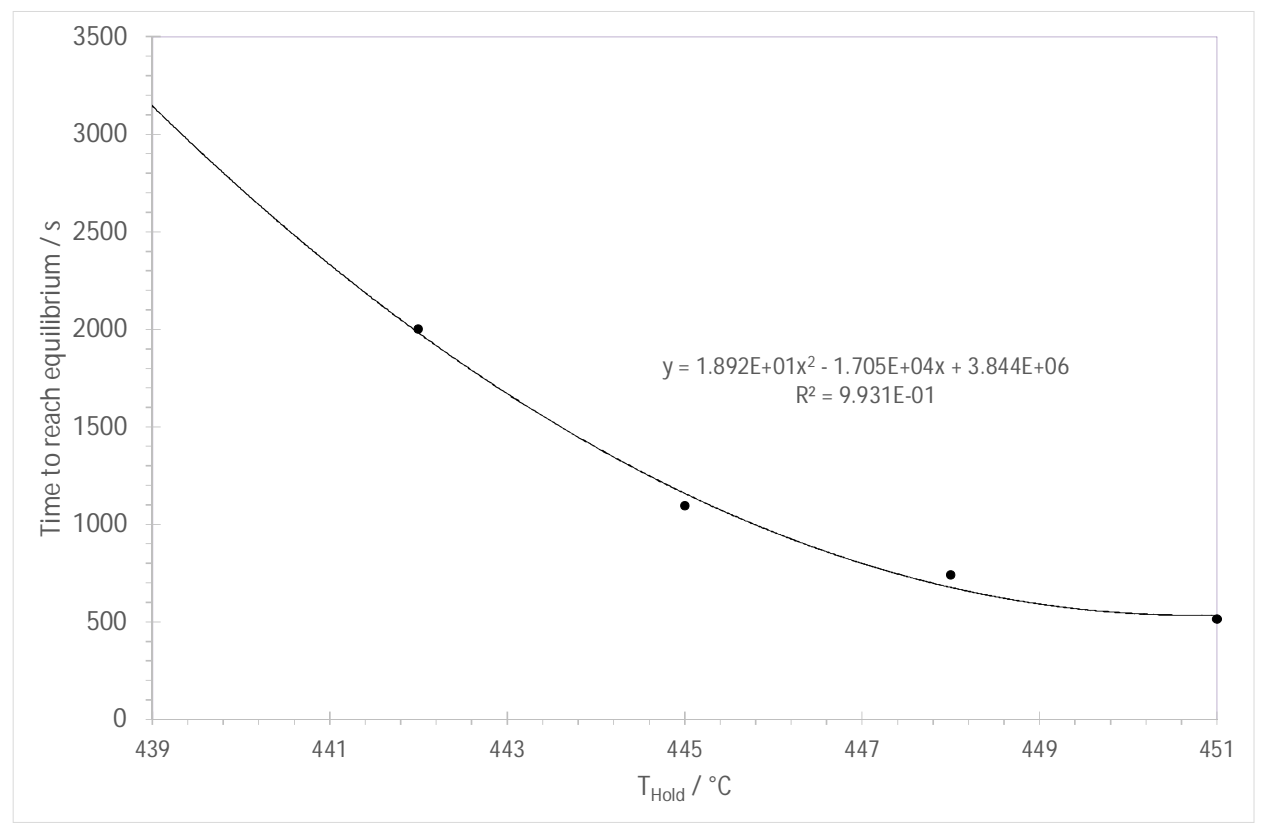

Figure 8. Time necessary to reach equilibrium as a function of the holding temperature $\mathrm{T}_{\mathrm{Hold}}$ for the $\mathrm{Ag}_{35} \mathrm{Cd}_{05} \mathrm{In}_{60}$ sample. An extrapolated value of $3145 \mathrm{~s}$ is calculated at $439^{\circ} \mathrm{C}$.

The extrapolated time value is $3145 \mathrm{~s}$. This value is of course dependent on the specific analytical expression chosen to perform the extrapolation however, this rough estimation shows that the time required to reach equilibrium at $439^{\circ} \mathrm{C}$ is close to the duration $(3600 \mathrm{~s})$ of the holding stage. The sample is probably not very far from equilibrium at the end of the holding stage.

Secondary heating: after holding, the sample is heated from $\mathrm{T}_{\text {Hold }}$ to $\mathrm{T}_{\text {Max }}$. The heat flow recorded during this stage is plotted vs time in Figure 9. A specific offset value has been applied to each curve in order to make them start at the same heat flow value $(=6 \mathrm{~mW})$. At $\mathrm{t}>600 \mathrm{~s}$, all the heating curves become linear and parallel. For each curve, a final baseline can be constructed and extrapolated to $t=0$. This baseline construction allows to divide the curves in two groups. After the initial thermal transient regime, in the first group, $427 \leq \mathrm{T}_{\text {Hold }} \leq 439^{\circ} \mathrm{C}$ (in black in Figure 9), the signal decreases and becomes lower than the baseline before returning to it. Such an endothermic deviation indicates the presence of a solid phase which melts in the heating run. The magnitude of the endothermic deviation increases with the solid fraction which is present at the beginning of the run, and obviously decreases as $\mathrm{T}_{\mathrm{Hold}}$ is increased and approaches the liquidus temperature. In the second group $442 \leq \mathrm{T}_{\mathrm{Hold}} \leq 451^{\circ} \mathrm{C}$, no endothermic deviations occur and the 4 curves (in red in Figure 9) are very close to each other. For these curves $\mathrm{T}_{\text {Hold }}$ is above the liquidus temperature and the sample is completely melted at the beginning of the run. Assuming that the sample was equilibrated at $439^{\circ} \mathrm{C}$, it is concluded that the liquidus temperature lies in the range $439-442^{\circ} \mathrm{C}$. 


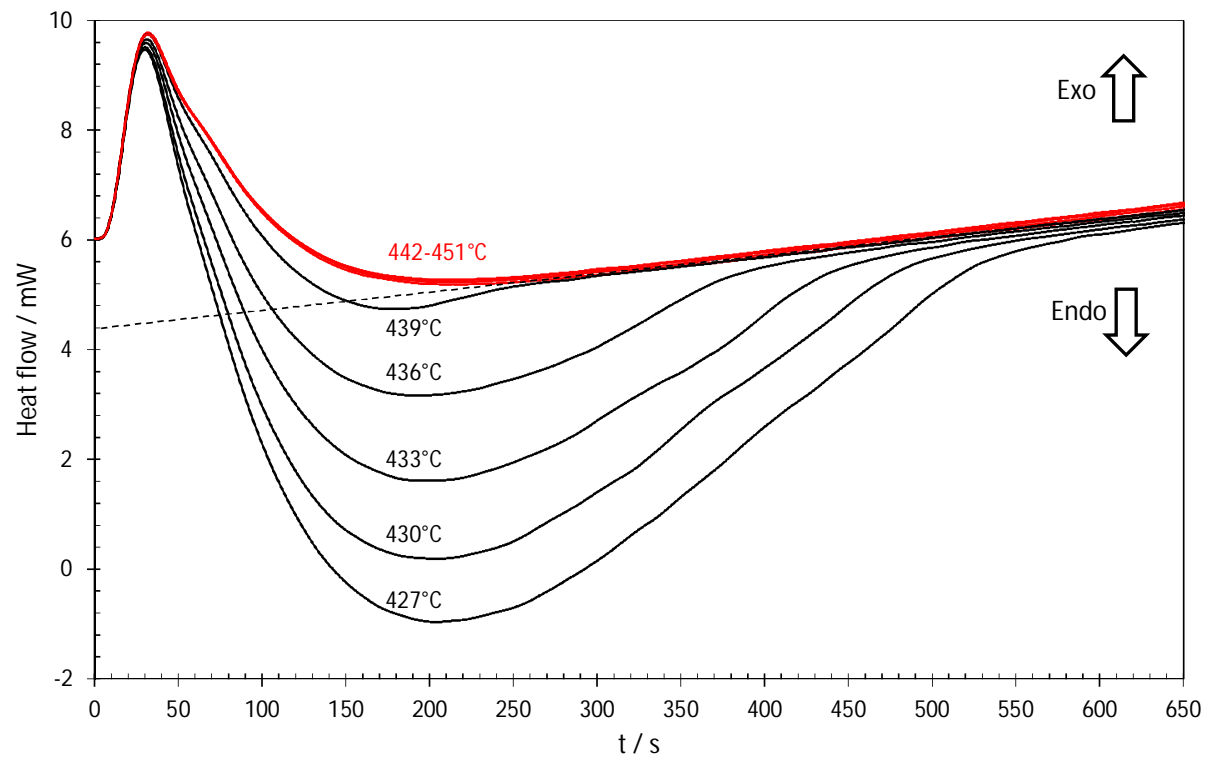

Figure 9. Heat flow recorded vs time during the secondary heating stages for the $\mathrm{Ag}_{35} \mathrm{Cd}_{05} \operatorname{In}_{60}$ sample. A different offset has been applied to each curve in order to make them start at the same heat flow value $(6 \mathrm{~mW})$. The extrapolated final baseline of the $439^{\circ} \mathrm{C}$ curve is plotted as a dashed line. State of the sample at the start of the heating is fully liquid for the red curves and partially solid for the black curves.

The thermal transient at the beginning of every secondary heating is a result of switching from an isothermal mode ( $\mathrm{T}=\mathrm{T}_{\text {Hold }}$ for 1 hour) to a constant heating rate $5^{\circ} \mathrm{C} \mathrm{min}^{-1}$ from $\mathrm{T}_{\text {Hold }}$ to $\mathrm{T}_{\text {Max }}$. An enlarged view of the heating traces during the initial period $(0-150 \mathrm{~s})$ is plotted in Figure 10. In the first group $\left(\mathrm{T}_{\text {Hold }}=427-439^{\circ} \mathrm{C}\right)$, the curves start to diverge after $30 \mathrm{~s}$ according to the solid fractions initially present. The 4 curves of the second set $\left(\mathrm{T}_{\text {Hold }}=439-451^{\circ} \mathrm{C}\right)$ are very well superimposed. Hence, this closer inspection shows no additional thermodynamic information in this part of the heating curves.

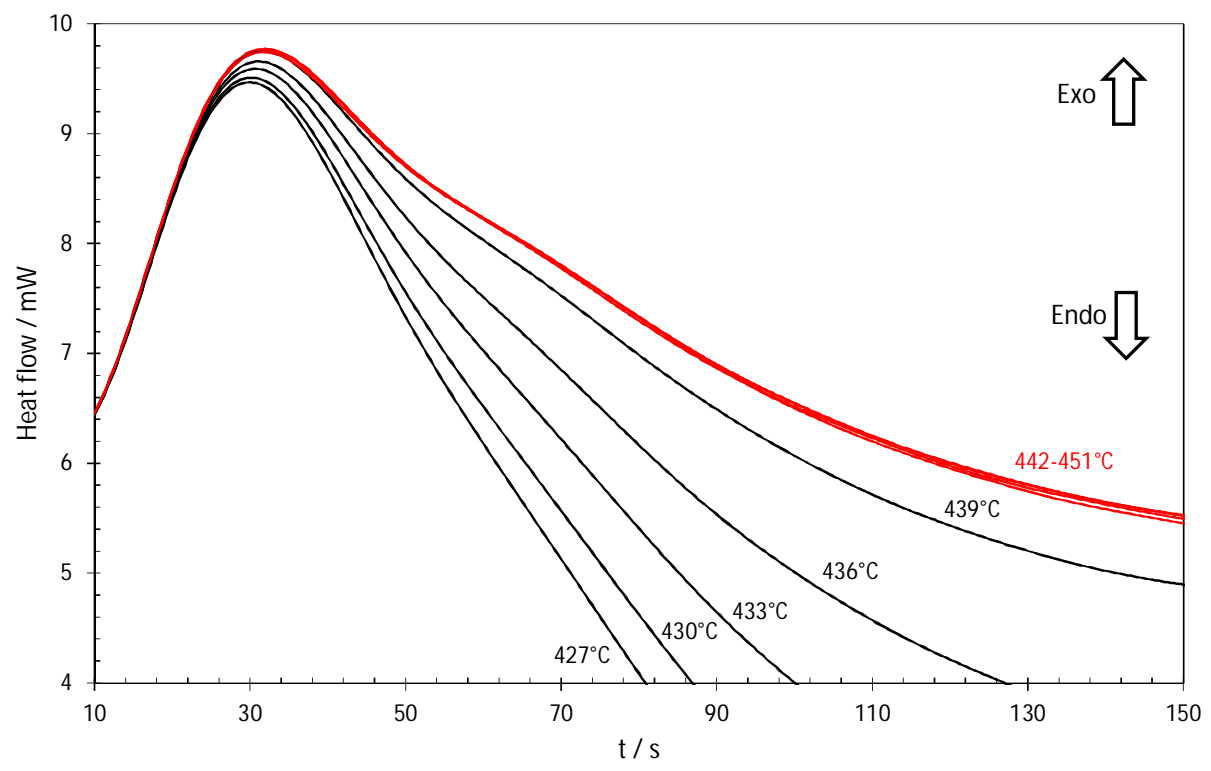

Figure 10. Enlarged view on the initial thermal transient of Figure 9. 


\section{Discussion}

In a dilute binary alloy in which the partition coefficient of the solute is lower than 1, the first solid that is formed on cooling at a typical constant rate of few ${ }^{\circ} \mathrm{C} \min ^{-1}$ is solute depleted compared to the average alloy composition. If diffusion is slow, e.g. in an alloy forming a substitutional solid solution, the composition gradients will not be levelled off on reheating the sample at a similar rate. As a consequence, the liquidus temperature determined on heating will be overestimated. This reasoning also holds for the three alloys investigated in the present work.

The liquidus temperature measured on cooling at a constant rate is obviously underestimated because of the undercooling required for nucleation of the solid phase as already mentioned.

Hence, the classical protocol allows to establish a temperature interval in which the equilibrium liquidus temperature is lying. Repeating the experiments at various heating and cooling rates helps in reducing the width of this interval and refines the estimation. However, the results of Table 2 show that the remaining uncertainty is still very large ranging from 13 to $30^{\circ} \mathrm{C}$ for the alloys under investigation.

IHDTA considerably reduces the uncertainty mainly by lowering the upper bound of the interval. The inherent weakness of the protocol being that, in general, the holding time which is required to homogenize the alloy at a given temperature is not known in advance, and a residual uncertainty in the lower bound of the interval cannot be avoided. Reducing this uncertainty requires to repeat the experiments with optimized values of the parameters, e.g. slower rates and increased holding times, the final choice being a compromise between the time length of the experiments and the target accuracy on the liquidus temperature. Combining the results of DTA and IHDTA also helps to better estimate the liquidus temperature.

The systematic study of a ternary system implies a large number of alloys and a standard protocol must be adopted. Time consuming optimization of the protocol for each composition is not always feasible. It is worth noting that the IHDTA protocol with one hour holding time presented in Figure 2 only lasts $100000 \mathrm{~s}(\approx 28 \mathrm{~h})$ which is considerably shorter than the corresponding classical DTA at $0.5,12,5$ and $10{ }^{\circ} \mathrm{C} \mathrm{min}-1(\approx 3$ days). This advantage disappears if the holding time is increased to several hours.

For the $\mathrm{Ag}_{40} \mathrm{In}_{60}$ composition, the liquidus temperature is measured in the range $451-454^{\circ} \mathrm{C}$ by IHDTA experiments. This estimation is quite close to the values of $455^{\circ} \mathrm{C}$ measured by Moser et al. [8] on heating at constant $0.5-$ $5^{\circ} \mathrm{C} \mathrm{min}^{-1}$ rates with a DSC and of $456^{\circ} \mathrm{C}$ found by Horrocks [6] using the Smith technique. It is also interesting to note that the DSC trace shown in Figure 4 of [8] for a $\operatorname{Ag}_{77.5} \operatorname{In}_{22.5}$ alloy shows no marked peak at the liquidus temperature but instead a sharp slope break. Our results confirm that:

- the value of $446.5^{\circ} \mathrm{C}$ measured by Bahari et al. [9] on heating at constant 0.5 or $1{ }^{\circ} \mathrm{C} \min ^{-1}$ rate is underestimated. From Figure 4 of [9], it is worth mentioning that the $446.5^{\circ} \mathrm{C}$ value is also abnormally low compared to the ones measured by the same authors on other compositions both richer and poorer in In.

- the value of $479^{\circ} \mathrm{C}$ measured by Robinson, also using the Smith technique as reported in [6], is largely overestimated.

For the $\mathrm{Ag}_{35} \mathrm{Cd}_{05} \mathrm{In}_{60}$ composition, our DTA and IHDTA experiments estimate the liquidus temperature in the range $437-442^{\circ} \mathrm{C}$.

For the $\mathrm{Ag}_{28} \mathrm{Cd}_{12} \mathrm{In}_{60}$ composition, the single available $423^{\circ} \mathrm{C}$ value of Robinson is not confirmed by our IHDTA experiments which indicate that the equilibrium liquidus temperature lies in the range $403-406^{\circ} \mathrm{C}$. Additional IHDTA experiments have been performed on this alloy with refined temperature increment of $1^{\circ} \mathrm{C}$, instead of $3^{\circ} \mathrm{C}$, between two consecutive holding temperatures and increased holding time of $3 \mathrm{~h}$, instead of $1 \mathrm{~h}$, at each $\mathrm{T}_{\text {Hold. The }} \mathrm{T}_{\text {Exo }}$ values recorded during the 12 cooling stages were all in a $2{ }^{\circ} \mathrm{C}$ range, the highest value being $395^{\circ} \mathrm{C}$. The results obtained with the two sets of parameters are consistent (Table 3) showing that the holding time is long enough to reach equilibrium. 


\section{Conclusions}

In Ag-Cd-In alloys, the equilibrium liquidus temperature is difficult to determine by classical DTA using constant heating and cooling rates. The diffusion is too slow to allow the sample state to follow the rate of temperature change and the signal is smeared over a large temperature range. On heating, the thermal signature of the liquidus crossing cannot be unambiguously determined and the large undercooling also prevents a direct determination on cooling.

The IHDTA method, operating closer to equilibrium conditions, considerably reduces the uncertainty in the liquidus temperature determination. This method will be extended to examine more ternary compositions in the less known $\mathrm{Cd}$ and In rich regions of the Ag-Cd-In ternary diagram as a support to a CALPHAD optimization of the ternary system.

\section{Acknowledgments}

The authors wish to thank the GDR CNRS $n^{\circ} 3584$ TherMatHT where fruitful discussions started and led to collaborations on the present project and particularly with M. Lomello-Tafin of the SYMME Laboratory, Université de Savoie (France).

\section{References}

1. Petti DA. Silver-Indium-Cadmium Control Rod Behavior in Severe Reactor Accidents. Nucl Technol [Internet]. American Nuclear Society; 1989 [cited 2015 Oct 23];84:128-51. Available from: http://epubs.ans.org/?a=34183

2. Benigni P, Hassam S, Decreton A, Mikaelian G, Gajavalli K, Barrachin M, et al. Enthalpy of mixing in the AgCd-In ternary liquid phase. J Chem Thermodyn [Internet]. Elsevier Ltd; 2017;107:207-15. Available from: http://linkinghub.elsevier.com/retrieve/pii/S0021961416304025

3. Snyder HJ. Primary Solid Solution Phase Boundary in Silver Corner of Silver-Cadmium-Indium Ternary System. AIME Metall Soc Trans. 1967;239:1385-91.

4. Krett V, Cleveland J. Thermophysical Properties of Materials for Water Cooled Reactors. IAEA-TECDOC-949. Vienna, Austria; 1997;1-280.

5. Bowsher BR, Jenkins RA, Nichols AL, Rowe NA, Simpson JAH. Silver-indium-cadmium control rod behaviour during a severe reactor accident. Rep AEEW-R 1991 [Internet]. 1986 [cited 2015 Oct 23];50. Available from: http://inis.iaea.org/Search/search.aspx?orig_q=RN:19051554

6. Horrocks PJ. Phase Diagram and Thermodynamics of the Ag-Cd-In Ternary Alloy Systems. Ph D. Thesis Manchester University; 1991.

7. Steinbrück M, Stegmaier U. Experiments On Silver-Indium-Cadmium Control Rod Failure During Severe Accident Sequences. Annu Meet Nucl Technol 4-6 may 2010. Berlin; 2010.

8. Moser Z, Gasior W, Pstrus J, Zakulski W, Ohnuma I, Liu XJ, et al. Studies of the Ag-In phase diagram and surface tension measurements. $J$ Electron Mater [Internet]. 2001;30:1120-8. Available from: http://link.springer.com/10.1007/s11664-001-0138-4

9. Bahari Z, Elgadi M, Rivet J, Dugué J. Experimental study of the ternary Ag-Cu-In phase diagram. J Alloys $\begin{array}{llll}\text { Compd } \quad \text { 2009;477:152-65. Available from: } & \text { [Internet]. }\end{array}$ http://linkinghub.elsevier.com/retrieve/pii/S0925838808017027

10. Bahari Z, Dugué J. Thermodynamic studies of the binary systems Ag-In and Cu-In. Eur Phys J Spec Top [Internet]. 2017;226:1137-42. Available from: http://link.springer.com/10.1140/epjst/e2016-60231-1

11. Ball RGJ, Bowsher BR, Dickinson S, Cordfunke EHP, Konings RJM, Rand MH. Reactor Safety Programme 1988-1991 Thermochemical Data Acquisition Joint Final Report. 1991. 
12. Hultgren R, Desai PD, Hawkins DT, Gleiser M, Kelley KK, Wagman DD. Selected Values of the Thermodynamic Properties of the Elements. Metal Parks, Ohio: American Society For Metals; 1973.

13. Moon K-W, Boettinger WJ, Kattner UR, Biancaniello FS, Handwerker CA. Experimental and thermodynamic assessment of $\mathrm{Sn}-\mathrm{Ag}-\mathrm{Cu}$ solder alloys. J Electron Mater [Internet]. 2000;29:1122-36. Available from: http://link.springer.com/10.1007/s11664-000-0003-X

14. Wu RI, Perepezko JH. Liquidus temperature determination in multicomponent alloys by thermal analysis. Metall Mater Trans A [Internet]. 2000;31:497-501. Available from: http://link.springer.com/10.1007/s11661-000-0285-X

15. Boettinger WJ, Kattner UR, Moon K-W, Perepezko JH. DTA and heat-flux DSC measurements of alloy melting and freezing. NIST Spec Publ [Internet]. 2006;1-90. Available from: https://ws680.nist.gov/publication/get_pdf.cfm?pub_id=853443 